expected from the breakdown of carbohydrate. The low yields of ethanol might be due to its retention in the cell or its resynthesis into carbohydrate.

When 100 per cent oxygen was used in the manometer flasks instead of air, the rate of carbohydrate degradation was further increased and more carbon dioxide was released. The rate of oxygen uptake was also greater than the rate in air. Table 2 shows the time course of endogenous metabolism under nitrogen, air and 100 per cent oxygen. In this particular experiment, the carbohydrate breakdown per flask in the first hour was $0.42 \mathrm{mgm}$. in the flask under nitrogen, $0.59 \mathrm{mgm}$. under air and $0.67 \mathrm{mgm}$. under 100 per cent oxygen.

These results indicate that in the strain of yeast used in these experiments, endogenous fermentation is stimulated by the presence of oxygen, the stimulation increasing with increasing oxygen tension. The level of oxygen uptake rises with increasing oxygen tension but remains small. It is interesting to compare this effect on reserve carbohydrate with the wellknown Pasteur effect, which refers to the inhibition of fermentation of external carbohydrate by oxygen and results in a sparing effect on the breakdown of carbohydrate.

I wish to thank the Directors of Arthur Guinness Son \& Co. (Park Royal) Ltd. for permission to publish this communication. I am indebted to Mr. A. J. R. Purssell for valuable discussion of results.

\section{E. Chester}

\author{
Research Laboratory, \\ Arthur Guinness Son \& Co. (Park Royal) Ltd., \\ Park Royal Brewery, \\ London, N.W.10. \\ August 20. \\ ${ }^{1}$ Chester, V. E., Nature, 183, 902 (1959). \\ Lindegren, C. C., Nagai, S., and Nagai, H., Nature, 182, 446 (1958). \\ Ogur, M., St. John, R. C., and Nagai, S., Science, 125, 928 (1957).

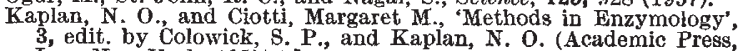 \\ Inc., New York, 1957).
}

\section{Carbohydrates of the Rampion, Campanula rapunculus $L$.}

Despite such studies as those of Chollet 1 it does not seem to be generally recognized how closely the watersoluble carbohydrates of the Campanulaceae resemble those of the Compositae. For example, this resemblance is not mentioned in recent books by Bonner ${ }^{2}$, Pigman $^{3}$, and Karrer 4 .

Chollet showed that several species of Campanula contain fructose polysaccharides resembling those of the Jerusalem artichoke. We have recently examined extracts of the fleshy roots of another species, C. rapunculus, the rampion, and find that they contain a series of non-reducing oligosaccharides indistinguishable on paper chromatograms from those of composites ${ }^{5}$. Fractionation by gradient elution with aqueous ethanol from charcoal-'Celite' columns showed that only one trisaccharide was present (as in Helianthus tuberosus ${ }^{6}$ ). This was crystallized and, as with $H$. tuberosus, shown to be $1^{F}$ - $\beta$-fructosylsucrose; it had a fructose : glucose ratio of $1.87: 1,[\alpha] v^{15+}$ $27 \cdot 6^{\circ}$, and the same infra-red spectrum as an authentic specimen.

When boiling-water extracts of the roots were left at room temperature for several days a precipitate appeared. This was a polysaccharide resembling inulin in its solubility, soluble in hot water (above $80^{\circ}$ ) but coming out of solution after freezing and thawing. However, it had $[\alpha] D^{21}-27^{\circ}$ and a glucose content of $5 \cdot 2$ per cent; typical specimens of inulin have $[\alpha]_{D}$ at least $-40^{\circ}$ and $2-3$ per cent glucose ${ }^{8}$.

After removal of this polysaccharide, a further fructosan fraction could be precipitated by the addition of two volumes of ethanol. This had $[\alpha]_{D^{21}}-29^{\circ}$ (glucose content: 3.4 per cent), thus resembling that described as 'fructosane $B$ ' by Chollet', which he showed to be very similar to the 'inulénine" fraction isolated by Tanret ${ }^{8}$ from $H$. tuberosus.

These findings would seem to argue a close evolutionary connexion between the Campanulaceae and Compositae. The review by Fuchs ${ }^{9}$ shows that the Lilifiorae, Glumiflorae and Compositae have been fairly extensively studied; but there is need for a survey, in the light of modern knowledge, and using newly developed analytical techniques, to determine the full extent of the occurrence of fructosans in the plant kingdom. Such a survey might cast useful light on some problems of classification ${ }^{10}$, and also help to correct the present tendency to regard starch as the usual form of carbohydrate reserve in plants.

I wish to thank Dr. V. C. Farmer, of the Department of Spectrochemistry of this Institute, for examining the infra-red spectrum of the trisaccharide.

\section{J. S. D. BACON}

Department of Biochemistry,

Macaulay Institute for Soil Research, Craigiebuckler,

Aberdeen,

Aug. 5.

1 Chollet, M. M., Bull. Soc. Chim. Biol,, 29, 824, 827 (1947).

2 Bonner, J., "Plant Biochemistry" (Academic Press, New York, 1950) Pigman, W. W., "The Carbohydrates" (Academic Press, New York,

1957),
Karrer, w., "Konstitution und Vorkommen der Organische Pfianzenstoffe" (Birkhäuser Verlag, Basel, 1958).

'Bacon, J. S. D., and Edelman, J., Biochem. J., 48, 114 (1951).

Aacon, J. S. D., and Bell, D. J., Biochem. J., 63, 200 (1956). A. St. G., and Nixon, D. A., Lancet, 273, 368 (1957).

s cf. Bell, D. J., and Palmer, A., J. Chem. Soc., 3763 (1952).

10 cf. Belval, H., and de Cugnac, A., Bull. Soc. Chim. Biol., 23, 74 (1941).

\section{RADIOBIOLOGY}

\section{Separation by Gamma-Irradiation of Two Elements at the Vby Locus in Trifolium repens}

THE $V^{b y}$ leaf-marking allele in Trifolium repens results in the production of a phenotype characterized by the presence of a broken white $V$ surmounted by a yellow tip (Fig. 1a). A separation of the two parts by

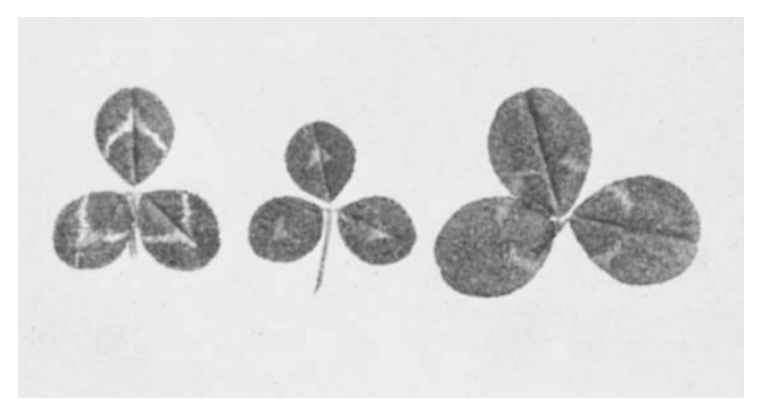
Fig. 1. Leaves of $T$. repens. $a$, Normal ; $b$, yellow tip phenotype;
$c$, white $V$ phenotype 